\title{
Deinking of Black Toner Ink from Laser Printed Paper by Using Anionic Surfactant
}

\author{
Mehari Abraha, Zebene Kifle \\ Department of Chemical Engineering, School of Chemical and Bio Engineering, Addis Ababa University, Addis Ababa, Ethiopia \\ Email address: \\ meharia727@gmail.com (M. Abraha),zebenek1@gmail.com (Z. Kifle) \\ To cite this article: \\ Mehari Abraha, Zebene Kifle. Deinking of Black Toner Ink from Laser Printed Paper by Using Anionic Surfactant. Chemical and \\ Biomolecular Engineering. Vol. 4, No. 1, 2019, pp. 23-30. doi: 10.11648/j.cbe.20190401.15
}

Received: April 22, 2019; Accepted: May 29, 2019; Published: June 13, 2019

\begin{abstract}
The objective of this research was to synthesize natural anionic surfactant from renewable material and use of this surfactant for ink removal from printed paper via flotation deinking in paper recycling process. The work included the preparation of the castor seed raw material, extraction of castor oil, preparation of anionic surfactant and deinking flotation of waste printed paper. Foamability and foam stability, critical micelle concentration and hydrophilic lipophilic balance of the surfactant was characterized and used to evaluate its fundamental deinking ability properties for the purpose of deinking flotation. The hydrophilic-lipophilic balance (HLB) of the fatty acid soap of 19.48 , average Foamability height of $49 \mathrm{~cm}$ and critical micelle concentration (CMC) of $0.0065 \mathrm{M}$ was obtained. Lab scale flotation deinking process was done and the basic flotation parameters like flotation time, fatty acid soap dosage and $\mathrm{pH}$ were optimized for evaluating deinking efficiency. The flotation deinking efficiency was probed by measuring the residual ink concentration of the hand sheet via Perkin Elmer spectroscopy before and after deinking flotation. The individual and interaction effects between the basic parameters were studied by using design Expert Software 6.0.8. For the deinking flotation, the maximum ink removal efficiency was determined to be $78.02 \%$ at the flotation time of $90 \mathrm{~min}$, fatty acid soap dosage of $1.5 \%$ and $\mathrm{pH}$ of 9 . Increasing flotation time from $30 \mathrm{~min}$ up to $90 \mathrm{~min}$ and decreasing fatty acid dosage from $3 \%$ to $1.5 \%$ and increasing of pH from 3 up to 9 were found to have increased the ink removal efficiency.
\end{abstract}

Keywords: Anionic Surfactant, Waste Paper, Flotation Deinking, Hand Sheet, Effective Residual Ink Concentration

\section{Introduction}

Paper is a sheet of fibers with a number of added chemicals that affect the properties and quality of the sheet. In Ethiopia both the local produced and the imported paper met the demand of the society. However, due to the existence of only one paper factory in the country, i.e. Ethiopian Pulp and Paper Factory located at Wonji, the majority of the supply is from import.

During 1998/99- 2004/05 E. C, the best supply offered by the domestic manufacturer was 12,685 tons while the yearly average consumption during the same period was 146,296 tons [1]. To avoid this shortage of paper in the country, it is necessary to recycle the waste paper by removing its ink and other dirties from the fiber.

The paper recycling is the process of wash, removing and bleaching unnecessary spots and other materials from printed paper therefore, this can be sold as an alternative to new produced paper manufacturing from original raw material. Recycling of wastepaper can have different uses and applications with respect to environmental, operating costs and energy consumptions compared to the various papers that produced directly from pulp. It has been estimated that for every ton of paper, which is made from $100 \%$ recycled wastepaper, 24 trees is saved. One ton of pulp made from deinked and bleached wastepaper requires $60 \%$ less energy than to manufacture a ton of bleached virgin Kraft pulp [2].

As the consumptions of paper increased from time to time, the need for a cheap resources grows radically, and the recycling of waste paper increased. The first step for recycling waste paper is the removal of inks from the printed paper because it affects the quality and brightness of paper. The main technique for removal of ink is deinking flotation. This is a process to selectively separate the hydrophobic ink particles from the hydrophilic fiber particles. 


\section{Materials and Methods}

\subsection{Materials and Chemicals}

The chemicals and analytical reagent grade used were sodium hydroxide, sodium sulfide, hydrochloric acid, distilled water, sulfuric acid, potassium hydroxide, N-hexane, phenolphthalein, Sodium chloride and ethanol. The equipments used during the experimentations includes laboratory autoclave, PerkinElmer spectrophotometer (AAU17 5839), aeration apparatus (Ch-EL254), Laboratory Pulper (EPP-3-01-5), Soxhlet extractor, Pulp disintegrator machine (EPP-3-01-6), Pressing machine (EPP-3-01-10), water bath(SBS40), sheet forming machine (EPP-3-01-9), and beating machine (EPP-3-01-05).

\subsection{Methods}

\subsubsection{Preparation of Anionic Surfactant}

Sodium stearate of the molecular formula $\mathrm{CH}_{3}$ $(\mathrm{CH} 2)_{16} \mathrm{COO}^{-} \mathrm{Na}^{+}$is anionic surfactant used for flotation deinking purpose. To manufacture this surfactants: a sample of the extracted refined oil was weighted into a $1000 \mathrm{~mL}$ glass beaker, and then $1000 \mathrm{~mL}$ of ethanol water mixture $(1: 1)$ was added to the same beaker followed by $25.4 \mathrm{~g}$ of sodium hydroxide. The beaker was then fit to a boiling water bath with a temperature of $60^{\circ} \mathrm{C}$ for 30 min with occasional shaking.

After being heated for about $30 \mathrm{~min}$, the odor of alcohol was disappeared, indicating the completion of the saponification reaction. A stock mass containing a mixture of the soap, glycerol, and excess sodium hydroxide was obtained.

To precipitate or "salt out" the soap, $150 \mathrm{~mL}$ of a saturated sodium chloride solution was added to the soap mixture while stirring vigorously. This process increases the density of the aqueous solution; therefore, soap was floated out from the aqueous solution and after this time it was put on filter paper to dry up.

\subsubsection{Experimental Flotation Deinking Process}

The pulp was charged into column and floated in the presence of surfactants. The ink particles were attached to the air bubbles due to their relatively high hydrophobicity and were floated to the surface of suspension, and the hydrophilic fibers were remain in the water phase. A scraper was used for foam removal over the course of flotation. The removed foam was collected in a reject tank. The yield of the flotation was calculated once the reject was dried and was deducted from the original floated slurry weight [3].

\subsubsection{Pulp Hand Sheet Preparation}

$138 \mathrm{~g}$ of oven dry pulp was mixed with 23 liters of water to make pulp slurry with consistency of $0.6 \%$. Pulp slurry was added in to a beating machine and beat up by circulating it. Freeness of slurry was checked out at each ten minutes beating interval. This was done by taking $333 \mathrm{ml}$ of slurry from the beater (this contains $2 \mathrm{gm}$ of moisture free fiber) and then dilute to $1000 \mathrm{ml}$ with distilled water and measured freeness value. When the freeness of pulp is $30 \mathrm{CSF}, 800 \mathrm{ml}$ sample was taken from beater and diluted to 2 liters of water $(0.17 \%$ consistency) and disintegrated at $1500 \mathrm{rpm}$ for five minutes. The beated and disintegrated pulp suspension was taken from the disintegrator and diluted to 4liters of water and agitated well by hand [4].

$404 \mathrm{ml}$ from the diluted suspension was taken $60 \mathrm{gm} / \mathrm{m}^{2}$ was prepared by sheet forming machine. Ones the sheets are prepared two stage pressing was followed by applying $0.47 \mathrm{MPa}$ pressure for four minutes by pressing machine. Then the stocks are removed from the press and attached to the drying plates in order to dry by oven at $130^{\circ} \mathrm{C}$ for 45 minutes. The prepared sheets were then tested for the residual ink concentration.

\subsubsection{Evaluation of Deinked Pulp}

The comparison of the blank hand sheet with those from the flotation runs allowed for determining the percentage of deinking efficiency. Deinking efficiency can be evaluated by measuring Effective Residual Ink Concentration (ERIC) of hand sheets made from the recycled paper before and after deinking. The hand sheets $(6 \mathrm{gsm})$ were prepared according to accepted procedure (TAPPI Standard) at Ethiopian pulp and paper industry located at Wonji. Hand sheets were prepared for measuring ink concentration of sheet.

Select the $950 \mathrm{~nm}$ filter position or modified spectral equivalent. Place the hand sheet on the instrument and read and record the reflectance of the sheet $\left(\mathrm{R}_{\infty}\right)$. Place the sheet on the instrument and back it with the black cavity, Read and record its reflectance $\left(\mathrm{R}_{0}\right)$. The scattering coefficient (s) of the sample at $950 \mathrm{~nm}$ was calculated by:

$$
\mathrm{S}=\left[\frac{\mathrm{R}_{\propto}}{\mathrm{W}\left(1-\mathrm{R}_{\infty}^{2}\right)}\right]
$$

Where $\mathrm{w}=$ grammage $\left(\mathrm{g} / \mathrm{m}^{2}\right)$ and where $\mathrm{R} 0$ and $\mathrm{R} \propto$ are expressed as decimals. Their ratio between $\mathrm{K}$ paper and Kink is defined as effective residual ink concentration (ERIC), with a unit of ppm.

$$
\begin{gathered}
\mathrm{K}=\mathrm{s} \frac{\left(1-\mathrm{R}_{\infty}\right)^{2}}{2 \mathrm{R}_{\infty}} \\
\mathrm{ERIC}=\frac{\mathrm{K}_{\text {sheet }}}{\mathrm{K}_{\text {ink }}} \times 10^{6}(\mathrm{ppm})
\end{gathered}
$$

Black inks have been shown to have an absorption coefficient of about $10,000 \mathrm{~m}^{2} / \mathrm{kg}$ [5]. This was considered to be a default value for this method (i.e. $\mathrm{kink}=10,000 \mathrm{~m}^{2 /} \mathrm{kg}$ ). If an insitu means is available for determining the absorption coefficient for the ink, the value used should be reported [5].

Deinking efficiency of the paper hand sheet could be calculated as follow:

$$
I E \%=\frac{E R I C U P-E R I C D P}{E_{\text {ERIC }}-E_{U P}-E_{U N P}} \times 100 \%
$$

Where, $E_{\text {RIC }}$ and ERIC $_{\mathrm{DP}}$ are the residual ink concentration for un deinked hand sheet (pulp) and deinked hand sheet (pulp) and ERICU $\mathrm{NP}_{\mathrm{NP}}$ is unprinted paper. 


\section{Results and Discussion}

\subsection{Characterizing of Anionic Surfactants}

The Critical micelle concentration was 0.0065. And hydrophilic-lipophilic balance values describe how the surfactant interacts with water soluble and water repellent substances. In deinking flotation it has been suggested that surfactants with an HLB value of 14-20 are optimal for deinking of paper and magazine mixtures [22]. Foamability is the foam volume immediately after the generation of the foam, and the liquid content of the foam.

\subsection{Effect of Deinking Flotation Process Variables}

\subsubsection{Effects of Flotation Time on Deinking Flotation}

As shown in Figure 1 below the ink removal efficiency was significantly affected by square flotation time. It can be seen from the figure that with increasing flotation time the ink removal efficiency increases up to it reaches $60 \mathrm{~min}$ and after this point reversing its trend because the pulp brightness can actually decrease somewhat with further increase of flotation time. Additionally, if the flotation time is increasing beyond its maximum point it can lead to lower fiber yield and removal of its whiteness. This long flotation time has an effect on darkening the fiber by removing the bright fillers and pigments. Besides this, when the flotation time is too low, the foam generated would not stable enough and they need enough time to be stable and able attach with air rather they would return back in to the fiber. This low flotation time has a diverse effect, since more ink needing to be collected means that an optimum flotation time was required to reach the target pulp brightness.

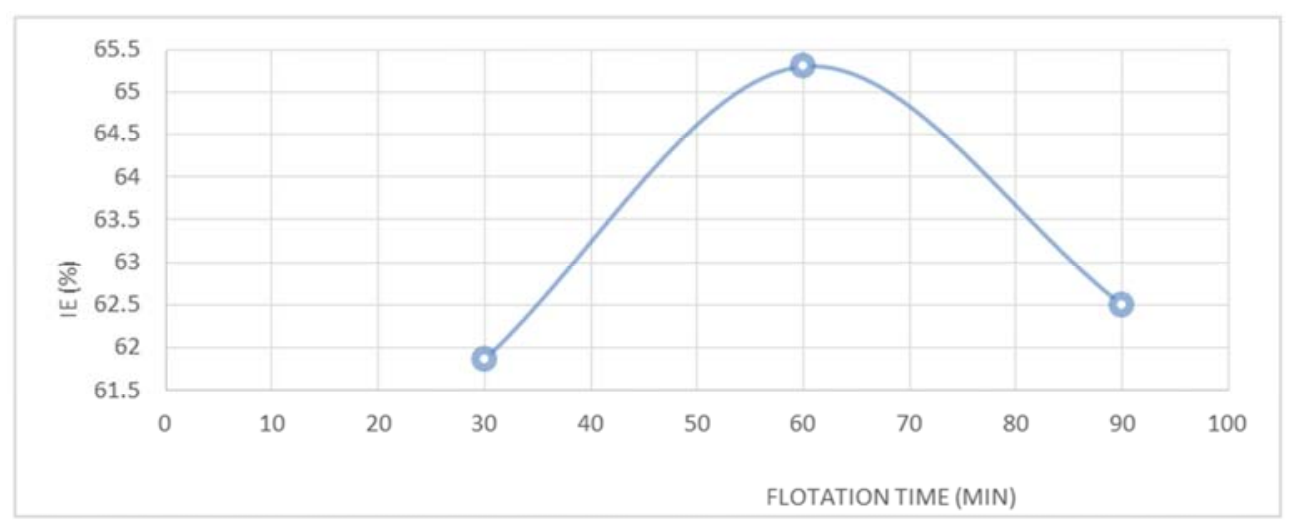

Figure 1. ink removal efficiency $V$ s flotation time.

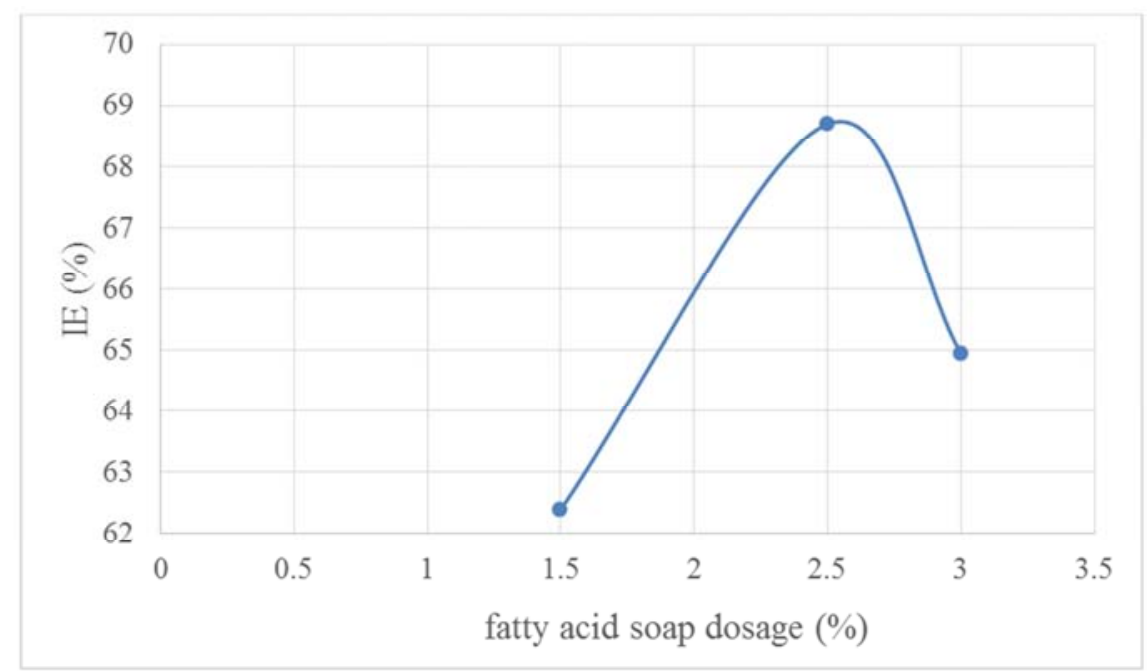

Figure 2. Fatty acid soap Vs ink removal efficiency.

\subsubsection{Effects of Fatty Acid Soap Dosage on Flotation Deinking}

As shown in figure 2 the ink removal efficiency was increased with fatty acid soap dosage but when it reaches $2.5 \%$ (based on ODF) changes its slope downward and this was due to the reasons of increasing their coagulation speed and absorb on the surface of the fiber, this leads to increase the hydrophobicity property of the fiber and This leads to the result of exactly stability of the ink particles and thus a reduced amount of ink attached to the air bubbles in flotation. Therefore the graph concludes excess dosage of fatty acid soap would affect the deinking flotation process. On the other hand, a lower limit for the dosage of fatty acid soap also seems to exist. Optimum fatty acid soap per dry fiber looks to be most favorable in this study. 


\subsubsection{Effects of pH on Flotation Deinking}

In deinking flotation, the $\mathrm{pH}$ of the pulp slurry was important because it helps to determine the extent of ionization, hydrolysis and the charge of surfactant on the surface of the fiber slurry. This in turn influences the possibility of the collector/fatty acid soap to attach on the fiber surface. Therefore, at the various ionized solid/liquid interfaces, $\mathrm{pH}$ can either helps or hinders the adsorption of the surfactant and contributing to greater or lesser selectivity of deinking flotation. Acidic medium deinking flotation has a risk to damage the equipment due to their more negative charges imposed on the contaminant and substrate to repulsive each other. The removal efficiency increased with increasing $\mathrm{pH}$ up to 9 , which means there was higher concentration of sodium hydroxide that was used to swelling up the fiber and helps to detach the ink from the fiber easily. And low $\mathrm{pH}$ levels also convert acids at the fiber surfaces to their unionized foams, making the fibers more hydrophobic and hence, more difficult to flotation.

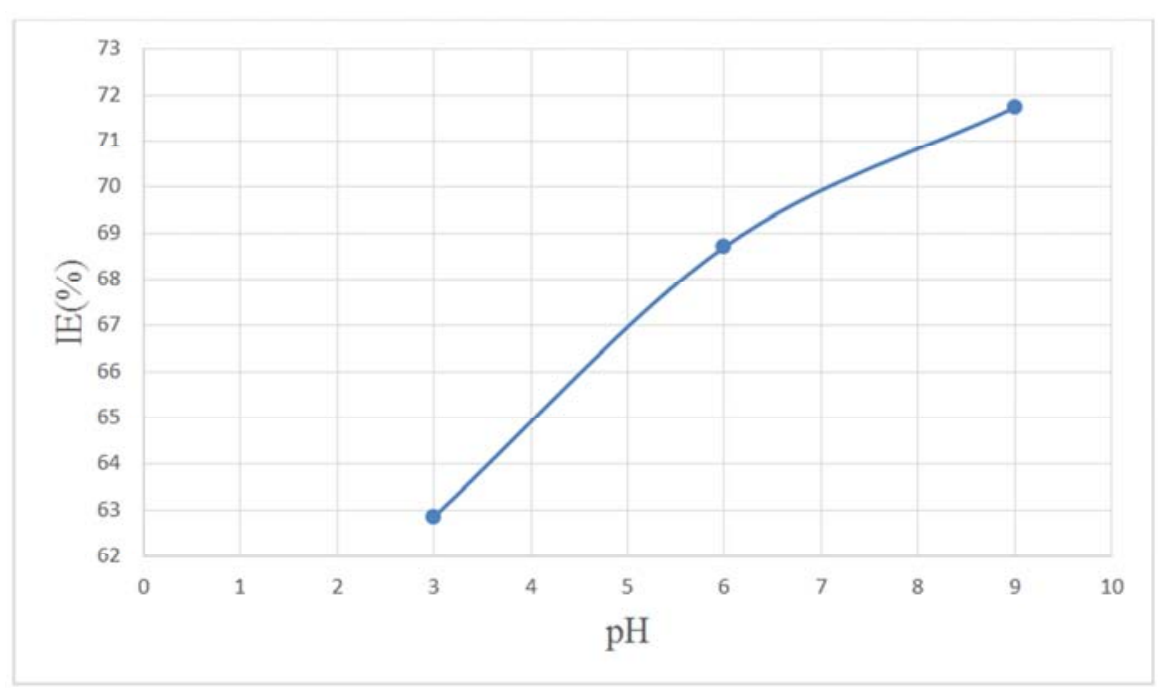

Figure 3. $p H V$ s ink removal efficiency.

\subsubsection{Interaction Effects of Flotation Time and Fatty Acid Soap Dosage}

The Figure 4 and 5 Below shows the 3D response surface and counter plots for the ink removal efficiency generated by the predicted model respectively. in the counter plot, ink removal efficiency increased until the flotation time reached $60 \mathrm{~min}$, and then it decreased. And also, increasing the fatty acid soap dosage from $1.5 \%$ to $2.5 \%$ led to increase in the ink removal efficiency and begins to decrease when the fatty acid soap dosage was further increasing from $2.5 \%$ to $3 \%$. Based on the below graphs (Figure 4 and 5), optimal conditions for ink removal efficiency was $66.5 \%$ with a desirability of 0.5311 at $2.5 \%$ (based on ODF) and $60 \mathrm{~min}$ flotation time with constant $\mathrm{pH}$ of 6 .

\section{DESIGN-EXPERT Plot \\ IE \\ $\mathrm{X}=\mathrm{A}$ : Flotation time \\ $\mathrm{Y}=\mathrm{B}$ : Fatty acid soap \\ Actual Factor \\ C: $\mathrm{pH}=6.00$}

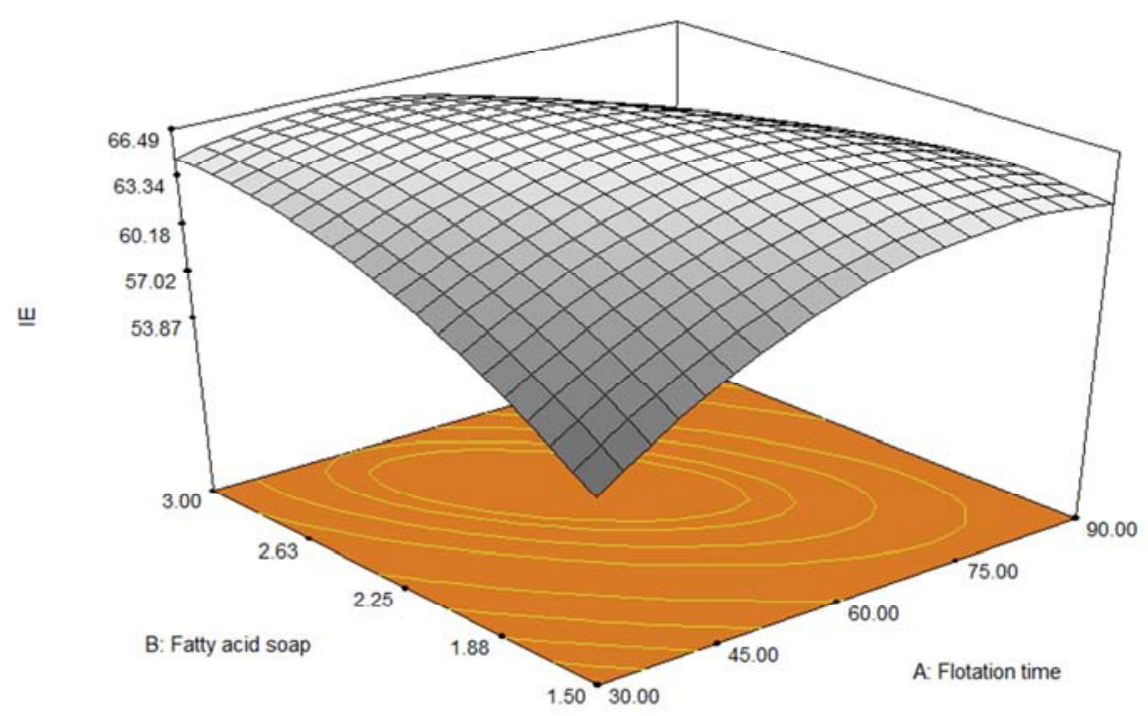

Figure 4. Surface plot of the interaction effect of flotation time and fatty acid soap on ink removal efficiency. 
DESIGN-EXPERT Plot

IE

- Design Points

$\mathrm{X}=\mathrm{A}$ : Flotation time

$\mathrm{Y}=\mathrm{B}$ : Fatty acid soap

Actual Factor

C: $\mathrm{pH}=6.00$

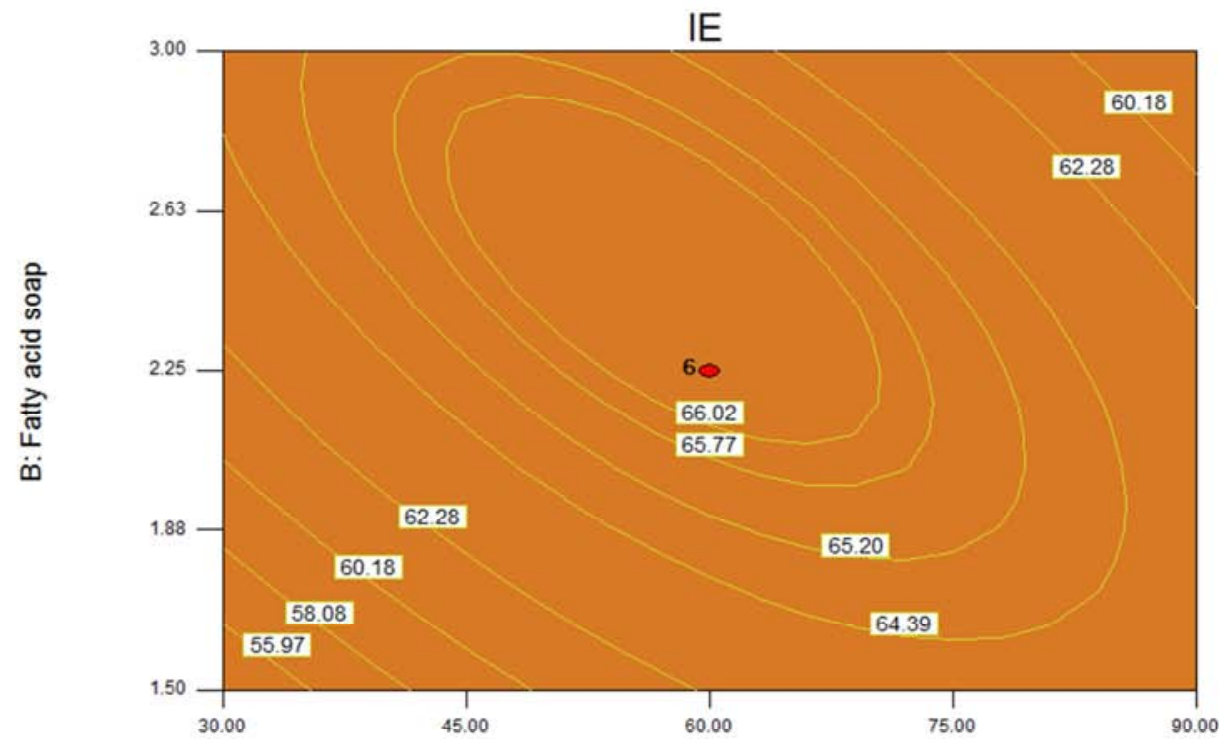

A: Flotation time

Figure 5. Contour Surface plot of the interaction effect of flotation time and fatty acid soap on ink removal efficiency.

\subsubsection{Interaction Effects of Flotation Time and $\mathrm{pH}$}

The effects of the deinking flotation parameters on the ink removal efficiency were plotted in Figure 6 in 3-D surface plot and in figure 7 in 2-D contour plots.

These figures shows the effect of the flotation time and the $\mathrm{pH}$ on the ink removal efficiency maintaining the fatty acid soap dosage constant at optimum value (i.e. $2.25 \%$ ). As can be seen, the interaction effect between the variables (flotation time and $\mathrm{pH}$ ) was obvious from both the 3-D response surface and the contour-line plots. The increase of flotation time from $30 \mathrm{~min}$ to $72.30 \mathrm{~min}$ leads to an increase of the ink removal efficiency from $61.09 \%$ to $72.4 \%$ and it begun to decreases when the flotation time was further increasing from $72.31 \mathrm{~min}$ to $90 \mathrm{~min}$ to $56.1 \%$. On the other hand, the effect of the $\mathrm{pH}$ was stronger at higher $\mathrm{pH}$. Moreover, the increase of the $\mathrm{pH}$ from 3 to 9 , increases the ink removal efficiency from $56.71 \%$ to $72.4 \%$.

\section{DESIGN-EXPERT Plot}

IE

$\mathrm{X}=\mathrm{A}$ : Flotation time

$\mathrm{Y}=\mathrm{C}: \mathrm{pH}$

Actual Factor

B: Fatty acid soap $=2.25$

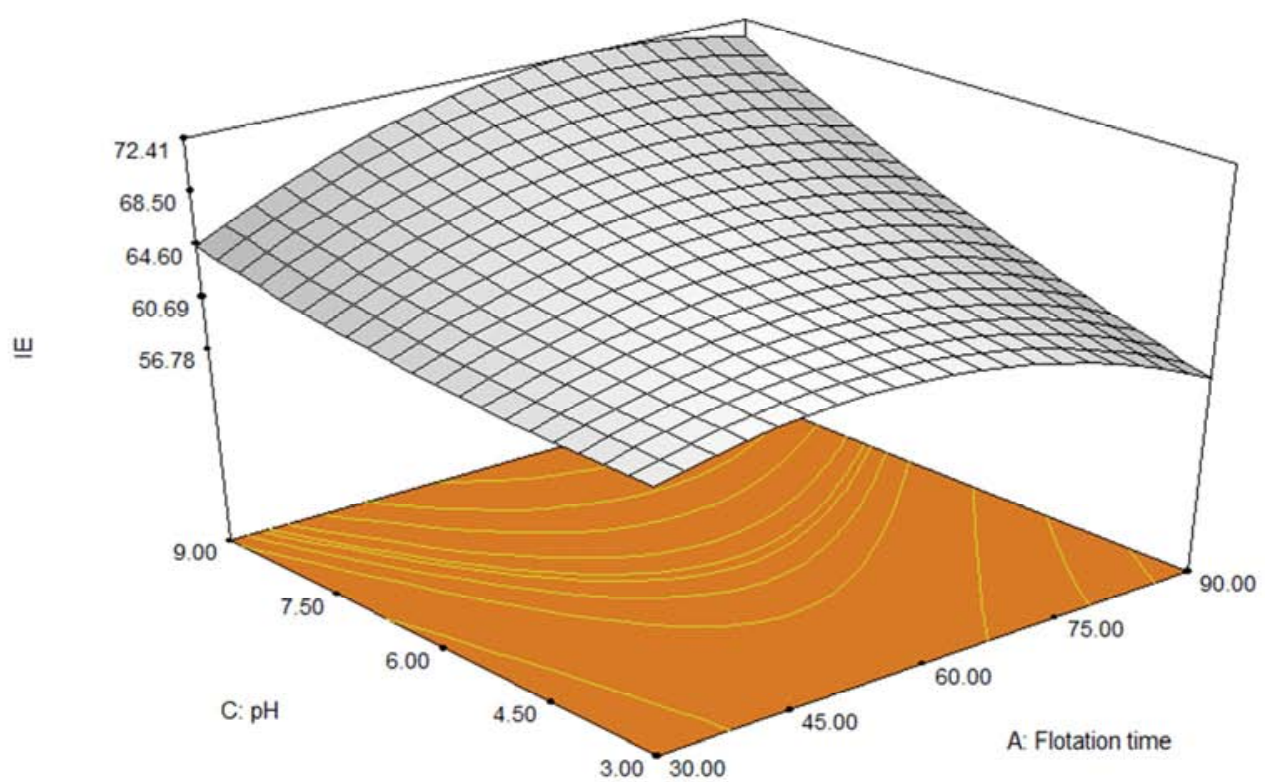

Figure 6. Surface plot of the interaction effect of flotation time and $p H$ on ink removal efficiency. 


\section{DESIGN-EXPERT PIOt}

IE

- Design Points

$X=A:$ Flotation time

$\mathrm{Y}=\mathrm{C}: \mathrm{pH}$

Actual Factor

B: Fatty acid soap $=2.25$

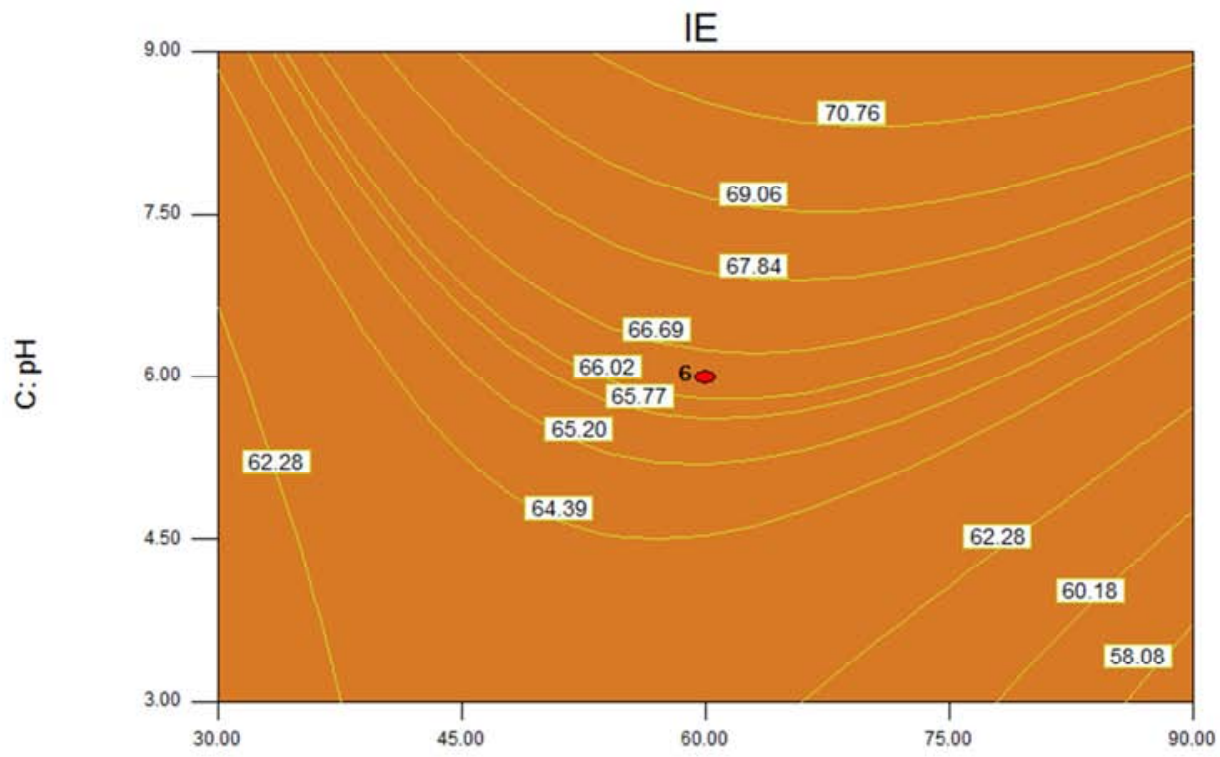

A: Flotation time

Figure 7. contour Surface plot of the interaction effect of flotation time and pH on ink removal efficiency.

\subsubsection{Interaction Effects of Fatty Acid Soap Dosage and pH}

The ink removal efficiency was increasing when the fatty acid soap dosage increases from $1.5 \%$ to $2.65 \%$ then begins to decrease when the fatty acid soap dosage increases further from $2.65 \%$ to $3 \%$. the ink removal efficiency was increasing with increasing the $\mathrm{pH}$ from 3 to 9 . Therefore the optimum deinking flotation efficiency was at $\mathrm{pH}$ of 9 and fatty acid dosage $2.65 \%$ (based on ODF) at constant $60 \mathrm{~min}$ flotation time.

\section{DESIGN-EXPERT Plot}

$\mathrm{IE}$

$\mathrm{X}=\mathrm{B}:$ Fatty acid soap

$\mathrm{Y}=\mathrm{C}: \mathrm{pH}$

Actual Factor

A: Flotation time $=60.00$

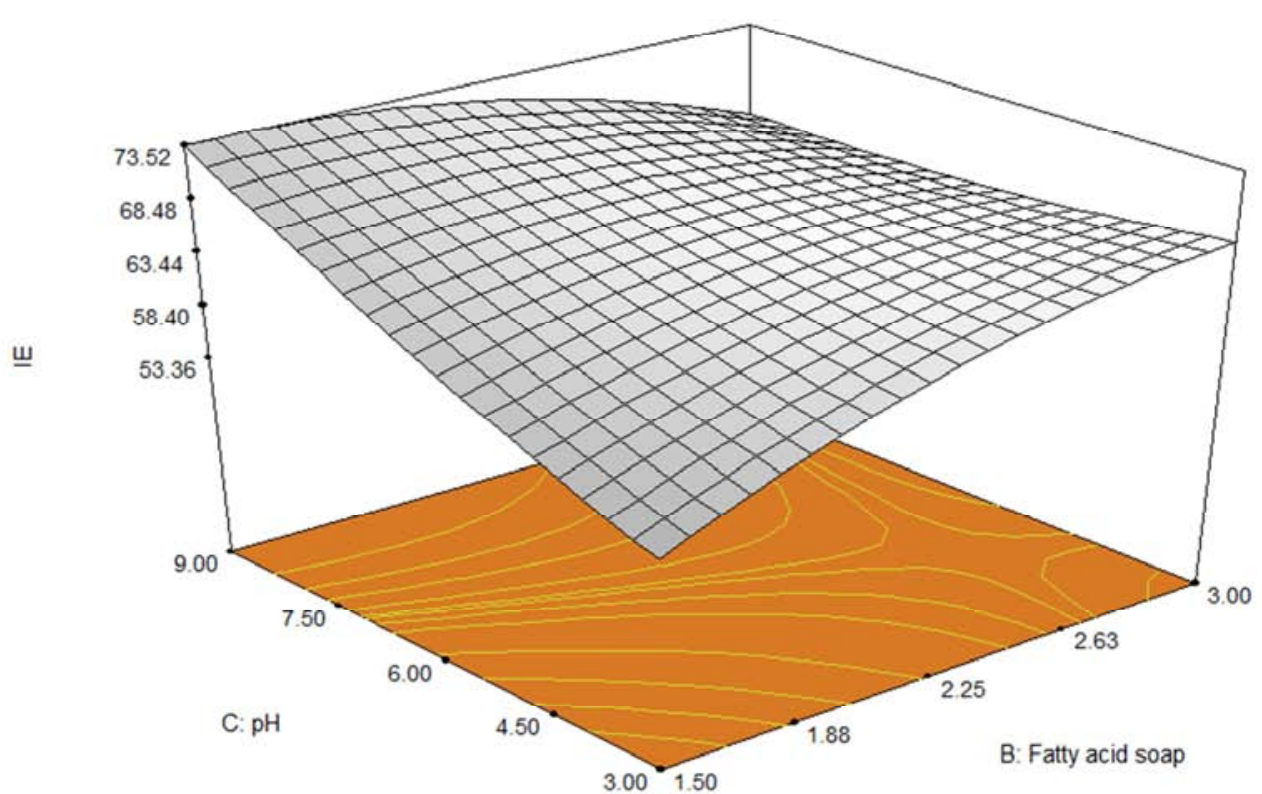

Figure 8. Surface plot of the interaction effect of fatty acid soap and $p H$ on ink removal efficiency. 
DESIGN-EXPERT Plot

IE

- Design Points

$X=B:$ Fatty acid soap

$\mathrm{Y}=\mathrm{C}: \mathrm{pH}$

Actual Factor

A. Flotation time $=60.00$

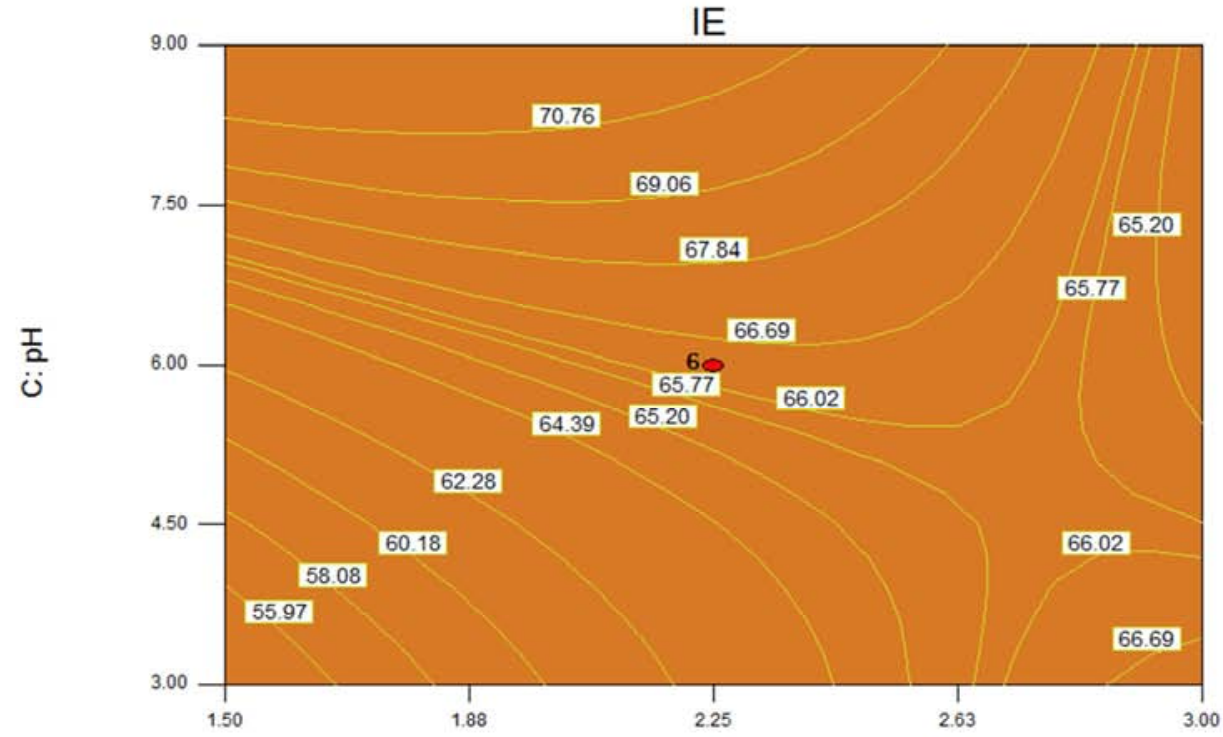

B: Fatty acid soap

Figure 9. Counter plot of the interaction effect of fatty acid soap and $p H$ on ink removal efficiency.

\section{Conclusion}

The three deinking flotation process parameters affecting the ink removal efficiency which are flotation time, fatty acid soap dosage and $\mathrm{pH}$ has been studied. A flotation time of $90 \mathrm{~min}$, amount of fatty soap of $1.5 \%$ (based on ODF) and $9 \mathrm{pH}$ results an optimal value of $78.0219 \%$ removal efficiency. The physicochemical properties determined for the fatty acid soap are HLB, CMC, foaming power \& foam stability. This work investigated deinking efficiency of two steps (pulping /flotation) using flotation cell equipped with aeration apparatus.

\section{Acknowledgements}

We would like to thank to Dr. Mesfin Redi, at Addis Ababa University, college of natural science, department of chemistry, for his viable support on measuring reflectance of hand sheet using Elmer -Perkin spectroscopy.

\section{References}

[1] Temesgen. (2011). Microsoft Word - 90. Small Scale Paper Making. doc.

[2] Turai L. D, Williams L. (1977). Tappi (Vols. (Vol. 60)., vol. 60 ,).

[3] Blaint J. (1992). The Process of Flotation Deinking, 1992 Contaminant Problems and Strategies in Wmtepaper Recycling Seminar Proceedings:113-120. Cincinnati, Ohio.

[4] RichardVenditti.(2002). LabManual:Handsheet Preparation. North Carolina State University:Department of Wood and Paper Science.

[5] Carre B., Galland G., and Saint Amand F. J. ((February 1995)).
"Estimation of Ink Detachment and Removal" Progress in Paper during Pulping and Kneading. TAPPI Recycling Symposium.

[6] Biermann C. (1996). Handbook of Pulping and Papermaking ( Second Edition ed.). San Diego, CA: ACADEMIC PRESS

[7] . Bobu E.; Ciolacu F.; Cretu A. (2008). Deinkability of mixed prints: alkaline vs. neutral deinking. Progress in Paper Recycling., 18 (1) 23-31

[8] Chin Li, Kevin Hipolit, Bhima R. Vijayendran. (1994.). Deinking agent of nonionic surfactants. United States Patent Li et al.

[9] Davide Beneventi1, Olivier Baudouin2 and Patrice Nortier1. (210). Semi-Empirical Modelling and Management of Flotation Deinking Banks by Process Simulation. France: INTECH opein science /open mind.

[10] Dobias, B., Klar, W., Schwinger, K. (1992). Flotation of pigments and inks from waste paper. Innovations in Flotation Technology.

[11] Dorris, G. M., and Nguyen. ( 1995). Flotation of model inks Part 11:Flexo ink dispersions with out fibers. $f$. Pulp and Paper Sci., (pp. 55- 62.).

[12] DoshiM. R. (1995). Optical brighteners: do we really need them?", Progress in Paper.

[13] Ferguson, L., (1992a). De-inking Chemistry Part I., Tappi J. 75(7): $75-83$.

[14] Krofta M, Wang LK., ( 1989). Total closing of paper mills with reclamation and deinking installa. Chelsea, MI: Lewis Publishers.

[15] MAK N., (1993). Characteristics of Fatty Acid as an Effective Flotation Deinking Collecter. 2nd Research Forum on Recycling, CPPA:, 145-152.

[16] Motson, H. (1999). "Nonionic surfactants. Cambridge: Karsoa, D. R., ed. The Royal Society. 
[17] PalaH M., Mota F., Gama M. (2005). Factors influencing MOW deinking: Laboratory scale studies. Elsevier.

[18] Richardson, D. E., Mineely, J., Pettit, P. R., Ash, G. H., Harden, P. E., and Parsons, T. (1992). The environmental impact of de-inking. Appita.

[19] Salager, J.- L. (2002). SURFACTANTS Types and Uses. Mérida-Venezuela: universidad de los andes.

[20] Scheibel J. J. (2004). The evolution of anionic surfactant technology to meet the requirements of the laundry detergent industry., (pp. 319-328).
[21] Sherbrooke, J. 2. (2001). Introduction to Stock Prep Refining. canada: Aikawa Fiber Technologies, 72 rue Queen.

[22] ThompsonC. G. (1992). Recycled paper. In The Essential Guide (pp. 64-67). Cambridge, MA, USA: The MIT Press.

[23] Zhao, Deng, Zhu. (2005). Roles of Surfactants in Flotation Deinking. Progress in Paper Recycling 14(1):41-45, November 2004. 